\title{
農業情報のための動画像通信システムに適した動的 な画像制御機能
}

\author{
井口信和 ${ }^{*} \cdot$ 内尾文隆 ${ }^{* *} \cdot$ 亀岡孝治 ${ }^{* * *}$ \\ •和歌山県工業技術センター \\ “和歌山大学システム工学部 † 640-8510 和歌山市栄谷 930 \\ …三重大学生物資源学部 † 514-8507 津市上浜町 1515
}

\section{要約}

本論文では，農業情報のための動画像通信システムに適した動的な画像制御機能を提案する。本 研究で扱う動画像通信システムは，画像による病害虫の遠隔診断や戋場などの監視・管理での利用 が可能である. 本研究で提案する機能の特徵は, 画像の受信者側からの要求と目的に応じて, 注目 領域の選択範囲と画像の量子化係数を動的に変更することである．提案する機能により，動画像通 信におけるQoSパラメータの調整作業が不要となる，さらに，使用している带域を使い切るように， これらの値を動的に制御することで，与えられた帯域の中で可能な限り多くの情報の転送が可能と なる。この機能を農業情報のための動画像通信システムに実装し，3つの帯域に対して画像による 病害虫診断に適用する実験を行った，実験結果より，いずれの带域においても，提案した機能が有 効に働き，与えられた帯域の中で可能な限り多くの情報が転送でき，ネットワーク帯域を有効に利 用できることを確認した。

$$
\text { キーワード }
$$

画像制御譏能, 動的 QoS 制御, 動画像通信, コンピュータネットワーク, 農業情報, 遠隔診断シス テム

\section{1.はじめに}

遠隔地の利用者のコミュニケーションを支援する技術として動画像通信, ビデオ会議システ ムが注目されている.多くのシステムが提案され, 遠隔会議, 遠隔教育, 在宅医療サービスな ど各方面での利用が始まっている.動画像通信により動きのある画像情報を扱うことが可能と なり, 音声や文字による情報伝達と比較して, より多くの情報を伝えることができる.

農業情報においても, 画像通信の利用が始まっている。農業生産現場と関係する組織間にお ける画像通信は極めて重要な技術である。この種の研究として,「WWW戋場画像獲得システム」 がある (二宮ら 1997).これは，WWW技術を用いて固場からの画像情報を定期的に獲得し， 围場監視·管理するためのリアルタイム静止画像システムである.これに対して本研究は, 動 画像通信を用いた農業情報システムの構築を目指すものである.WWWを用いた静止画像転送シ ステムと我々が開発を進めている動画像通信システムの使い分けによって,より的確な情報を 遠隔地に居ながらにしてリアルタイムに獲得することが可能となる.

我々は,これまでの研究において, 動画像通信の利用により農作物に発生した病害虫の診断 をコンピュータネットワーク上で実施する遠隔診断システムを開発した(井口ら 1998a，井 
ロら 1998b, Iguchi et al. 1998).これらの研究により, 病害虫の遠隔診断システムに要 求される機能を明らかにするとともに, 狭帯域回線上で動画像を効率よく転送するための機能 である注目領域の選択機能，および受信者側から画像の画質などのQoS(Quality of Services) をコントロールするための機能であるQoSコントロール機能を開発し, 実験によっ てこれらの機能の遠隔診断における有効性について確認した.

これまでに開発してきた病害虫の遠隔診断システムは, ISDNやアナログ電話回線のような 低速なネットワーク上での動画像の転送を可能とする動画像通信システムであるため, 病害虫 診断だけでなく画像情報を用いた圃場やハウス内の監視·管理など様々な場面での利用が可能 である.画像通信を用いて固場やハウス内を監視する場合, 監視したい場所を変更するなど撮 影シーンの変更がしばしば発生する.また、病害虫の診断においても,観察する対象物を動か したり, 観察する角度を変更する場面は多い.この時, 転送する画像は, 動いている領域が多 く含まれる動画像となる。動画像通信では, 画像圧縮技術として, 動き補償付き予測符号化方 式や条件付き画素補充方式が利用される(テレビジョン学会 1993). 動き補償付き予測符号 化方式は, 画素の動きに関する情報を利用することで, 画像圧縮の効率を上げている.条件付 き画素補充方式では,動きの大きな画像領域を優先的に転送することで画像圧縮の効率を上げ ている.したがって,動画像通信では,一画面中における動いている領域の割合が多い画像は, 動いている領域の割合が少ない画像と比較して, 転送する情報量が多くなる.また,使用して いる回線の帯域幅を越える情報量のデータを転送することはできない.したがって,動画像通 信においても情報量の大きな画像を転送しようとすると, 回線の帯域が不足し,超過した情報 はすべて破書される.このため,コンピュータ・ネットワークを用いたビデオ会議システムな どを利用している場合に, 撮影対象の人物が大きく動くと, コマ落ちが発生し, ぎくしゃくし た画像となってしまう。この場合には, 動画像のサイズ, 画質, フレームレートなどのQoSを 調整し,転送する動画像の情報量がネットワークの帯域幅以下になるようにしなければならな い.我々が,これまでに開発してきた機能を利用する場合には, 画像の受信者がそれぞれの場 面に応じて画像のQoSを変更すればよい.しかしながら,一般の利用者はもちろん, 操作に慣 れている利用者にとっても，QoS設定作業は複雑で困難である. 各QoSパラメータを独立に操 作しながら,それらをうまく組み合わせて, その時々の場面に適した画像を得ることは難しい. この場合, 画像のQoSを動的に制御する機能が有効である。これにより, 通信開始時のQoS設 定や場面変更時のQ 0 S 設定作業が不要となる.さらに, ISDNなどのように使用できる帯域幅 が一定で, 保障されている場合には, 使用している帯域を使い切るようにQoSを動的に制御す ることで,与えられた帯域の中で可能な限り多くの情報を利用者に提供することが可能となり, 限られた帯域が有効に活用できる.このような背景から, 本研究では, 農業情報のための動画 像通信システムに適した動的な画像制御機能として, 動的QoS制御機能を開発した.動的QoS 制御機能の実装により,開発してきた動画像通信システムを農業情報における多様な場面に対 応させることが可能となる。

本論文では, 農業情報のための動画像通信システムにおける動的QoS制御機能を提案する. 本研究で提案する機能の特徵は, 画像の受信者側からの要求と場面に応じて, 注目領域の選択 範囲と画像の量子化係数を動的に変更することである.提案する機能により, 通信開始時の QoS設定や, 場面変更時のQoS設定作業が不要となる.さらに, 使用している帯域を使い切る 
ようにQOSを動的に制御することで, 与えられた帯域の中で可能な限り多くの情報を利用者に 提供することが可能となる。

\section{2. 動的 $0 \circ S$ 制御機能}

\section{1 課題}

これまでの研究において, 病害虫の診断をコンピュータネットワーク上で実施する遠隔診断 システムのための機能を開発した。これらの機能を実装したビデオッールは, ISDNやアナロ グ電話回線のような低速なネットワーク上での動画像の転送を可能とするため, 病害虫診断だ けでなく画像情報を用いた戋場やハウス内の監視·管理など様々な場面での利用が可能である. 開発した機能は，1)注目領域の選択機能,および, 2) 注目領域の選択範囲, 画像の量子化係 数(quality) 䇽よび色数(カラーか白黒か)を画像の受信者側からコントロールできるQOS ントロール機能である.さらに, 注目領域と非注目領域の画像のQOS 独立に制御すること ができる.これらの機能をvic（McCanne et al. 1995, Jacobson et al. 1996) に追加 し,このビデオツールを使用した実験結果から，狭帯域回線での画像を使った遠隔診断が可能 であることを確認した. vicは、インターネットおよびM-boneで広く利用されているビデオ 画像転送ツールである。

同時に以下の課題が指摘された.

*コントロールできるQOSのパラメータは複数あり,それらは互いに独立して変更できる.こ のパラメータをうまく組み合わせることで, その時々の場面に適した画像の転送が可能とな る.しかし，一般の利用者はもちろん，操作に慣れている利用者にとっても，Q0S設定作業 は複雑で困難である.各Q 0 Sパラメー夕を独立に操作しながら,それらをうまく組み合わせ て,その時々の場面に適した画像を得ることは難しい。

* 病害虫の観察や圃場の監視を進めていく段階によって,撮影対象物の变更や観察するポイ ントの変更が頻繁に発生する.観察を進めながら, 同時にQoSパラメータをその都度変更す る作業は受信者の負担となる.

* 画像転送の開始時は, 利用する帯域と対象物, 観察するポイントなどから予測して,その 観察に適した画像が得られるようにパラメータをあらかじめ組み合わせることになる.しか し，その場面に適した画像が得られるようなパラメータの組み合わせをあらかじめ予測して 見つけることは容易ではない。

* 開発した機能の効果により,狭帯域であっても場面や画像の性質によっては帯域に余裕が できる場合がある。この場合には, 帯域が許す範囲まで, QoSを操作し, 注目領域の選択範 囲を広げたり，画質を上げることが可能である.しかし，観察を進めながらのQoSの操作は 面倒であるため, 最初に設定したQoSのまま画像転送を進めることが多い。この場合, 帯域 を使い切らないため,ネットワークの利用が非効率となってしまう.

これらの課題を解決するために, 動的QOS制御機能を開発し,ビデオツールに実装した. 本 論文で提案する機能の特徽は, 画像の受信者側からの要求と場面に応じて, 注目領域の選択範 囲と画像の量子化係数を動的に変更することである.図 1 にビデオッールの概観を示す. 


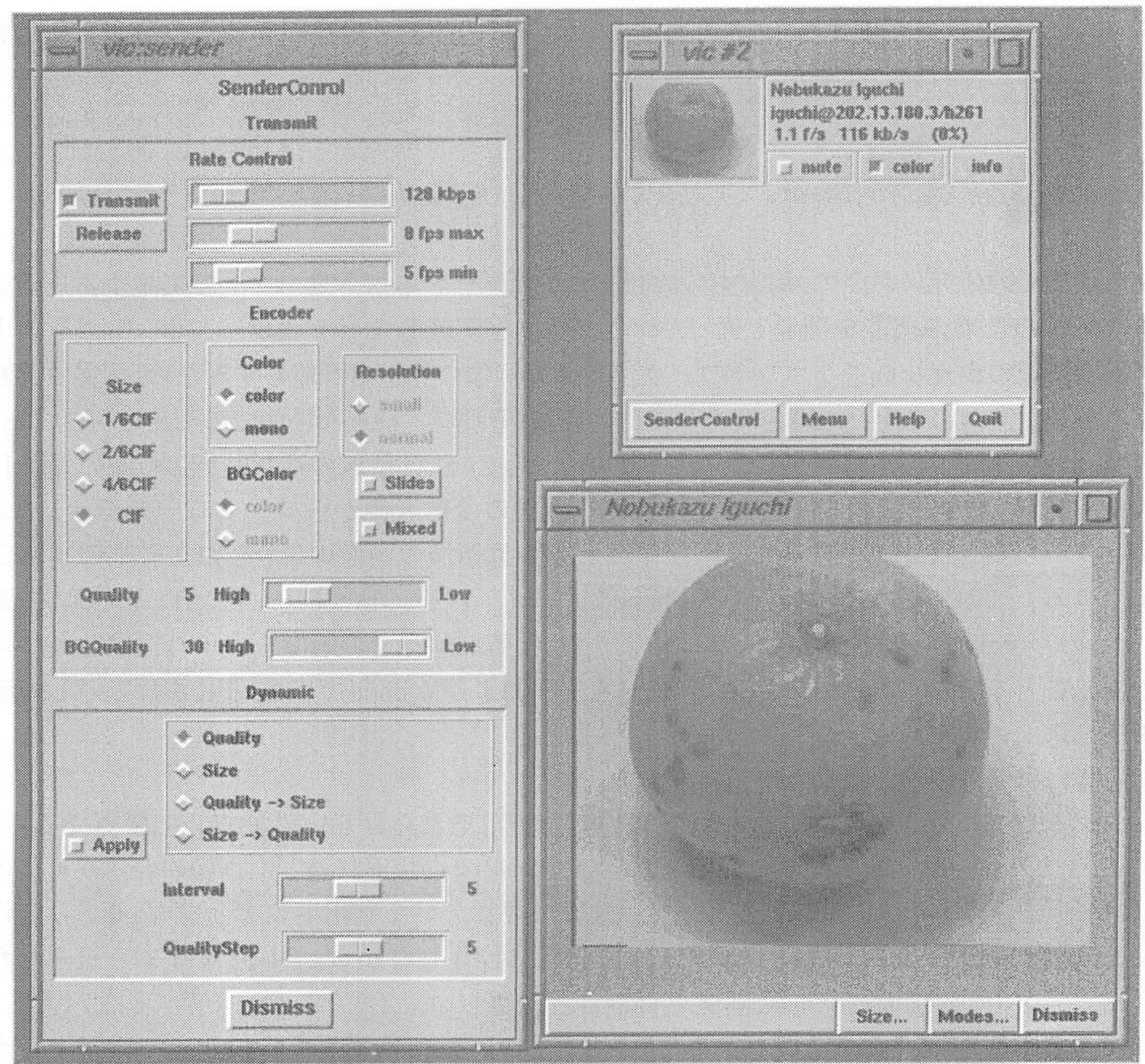

図 1： 開発したビデオッールの概観(受信側)

\section{2 動的 $0.0 \mathrm{~S}$ 制御機能の動作}

本論文で提案する動的QoS制御機能の動作を以下に述べる。まず, 画像送信側のビデオッー ルに対して,あらかじめシステムが接続しているネットワークの带域, およびフレームレート の最大值と最低確保值を設定しておく.動的QoS制御機能の利用が開始されると, 送信側のビ デオツールは, その時々のフレームレートの值が, あらかじめ設定した最低確保值以上あるか 否かを判断する.こ机により以下の処理のいずれかを実行する.

1 ) フレームレートが最低確保值以上ある場合.

接続しているネットワークの帯域 (以下, 設定帯域) と, 送信する画像が必要とする帯域 (以下, 必要帯域)の比較を実行し, 必要帯域が設定帯域に対してある割合未満の場合に, あ らかじめ利用者が選択したQOSパラメータを決められた手順に従って变更する。すなわち, 必要帯域 $<\alpha \times$ 設定带域 ただし, $0<\alpha<1$ 
を満たす時, QoSの変更を行う.この場合, QoSは必要帯域を多くするように変更される.例 えば, 注目領域の選択範囲が選択されている場合, 選択範囲を広くするように変更される. 2 ) フレームレートが最低確保值未満の場合.

あらかじめ利用者が選択したQoSパラメータを決められた手順に従って変更する.この場 合, QoSは必要帯域を少なくするように変更される.例えば, 注目領域の選択範囲が選択さ れている場合, 選択範囲を狭くするように変更される.QoSの変更は,フレームレートが最 低確保値以上になるまで続く.

送信側のビデオッールは，上記の動作を繰り返し，QoSを動的に制御する．各QoSパラメー タの值は, 受信側ビデオツールからの設定が可能である.

\section{3. 動的 $0 \circ S$ 制御機能の実装}

前述の動作を満足する機能を開発し,農業情報のための動画像通信システムに実装した.今 回,開発した機能では, 受信側ビデオッールから動的QoS制御に関する要求を全て設定するこ とができる．受信側ビデオッールの要求を送信側ビデオツールに伝えるために, RTCP (RTP Control Protocol) を利用した（Schulzrinne et al. 1996）。受信側から設定できる項目 を以下に述べる.これらの項目は,動的QoS制御機能の利用が開始された後においても変更が 可能である.

1. システムが接続しているネットワーク回線の帯域 (設定帯域). 本研究では, ISDNなどの ように,帯域幅が一定で保障されているネットワーク回線の利用を想定している.

2. フレームレートの最大值と最低確保值. 最大值はvicがもともと有している項目である. これを受信側から設定可能とした.最低確保值は,利用者が最低必要とするフレームレート を設定する.最小值として0を設定することができる.標準設定では, 最大值を $8 \mathrm{fps}$, 最低

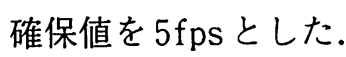

3. 前述の 2.2 の)で述べた $\alpha$ の値. $0<\alpha<1$ の範囲で自由に設定できる. 標準設定では, 0.8 とした。

4. 動的 QOS 制御機能の動作の開始・停止.

5. 制御するQoSパラメータの選択. 今回は, 注目領域の選択範囲と画像の量子化係数の $2 つ$ とした.

6. QoSの変更を判断する間隔. 今回は, 一定時間ごとにフレームレートの值を監視する. 時 間間隔は, 約 1 秒に 1 回から約 10 秒に 1 回まで 1 秒間隔で自由に設定できる. 標準では, 5 秒に 1 回とした。

7. 量子化係数を変更するステップ間隔.ここでいう量子化係数は,量子化テーブルの情報で ある.量子化係数は画像デー夕を符号化する際の量子化ステップサイズを与える.量子化係 数と量子化ステップサイズの関係を以下に示す.

量子化ステップサイズ $=2(1+$ 量子化係数 $) \quad($ 量子化係数 $=1, \cdots, 31)$

vicでは，量子化係数はquality 值として与えられ，1，，30 の範囲で選択すること が可能である.この值によって画像品質を指定できる.混乱を招きやすいので注意が必要で あるが, quality=1によって最も高い品質の画像を得ることができ, qual ity=30によって 最も低い品質の画像となる。ここでは、変更する間隔を1ステップごとに変更する設定から 
10ステップごとに変更する設定まで1ステップ間隔での自由な設定を可能とする.標準で は, 5 ステップずつ変更する.

次に, 今回設定したQoS変更のルールを示す. 以下に示す1)，2）では, 選択したパラメー 夕のみを変更させる．3）,4）では，2種類のパラメータに優先順位を決め, その順位にした がってQoSを希望值まで変更する.量子化係数の希望值は1, 注目領域の選択範囲の希望值は CIF (Common Intermediate Format)のサイズとした. CIF はテレビ電話やテレビ会議用符号 化の規格として標準化されているH. 261で利用する画像フォーマットであり, 352 画素 $\times 288$ ラインのサイズである。

1) quality

量子化係数を 30 (最低) から 1 (最高)までの範囲で変更する. 変更するステップ間隔は, 受信者側から設定する.標準設定では 5 ステップずつ変更する.

2 ) size

注目領域の選択範囲について，1/6CIF，2/6CIF，4/6CIF，CIF の4段階の変更を行う．1/ $6 \mathrm{CIF}$ とは, CIF に対して画像の中心部分の約 $1 / 6$ の範囲の画像をいう．2/6CIF，4/6CIF も同様の画像を示す。

3) quality $\rightarrow$ size

まず, 量子化係数を 1 まで変更し, 次に注目領域の選択範囲をCIF まで変更する. 例とし て，量子化係数を 30 , 注目領域の選択範囲を1/6CIFに設定して始めた場合, 量子化係数 を 1 まで5ステップずつ変更し, さらに帯域に余裕があれば, 注目領域の選択範囲をCIF まで変更する。

4) size $\rightarrow$ quality

上記の順序を逆にしたもの.

\section{4. 実倹}

\section{1 実験環境および実験方法}

提案した動的QoS制御機能の動作と有効性の確認を目的として, 利用実験を行った。送信側 にSGI Indy (200MHz MIPS R4400SC)を用い，画像入力用のビデオカメラを接続した，受信 側にはSGI Indy(150MHz MIPS R5000)を使用した。実際の運用に近いネットワーク環境で 評価するために, 2台のワークステーションはISDNシミュレータを介してISDNによる接続を 行い, PPP(Point to Point Protocol) (Simpson 1994)およびMP(PPP Multilink Protocol) (Sklower et al. 1996)を用いて通信した.

ネットワーク帯域として $32 \mathrm{kbps}, 64 \mathrm{kbps}, 128 \mathrm{kbps}$ の3種類について実験した. $32 \mathrm{kbps}$ 拈よ び64kbpsの場合には，ISDNのBチャンネル1本を利用し，PPPを用いて通信した。128kbps の場合には，ISDNのBチャンネル2本を利用し，MPを用いて通信した。

実験の対象には, かいよう病の発生したネーブルオレンジ（学名：Citrus sinensis Osbeck. ) を用いた. 観察したい部分が画面中央になるように撮影する。いずれの実験におい ても，QoSの初期設定值は, sizeは1/6CIF, qualityは30とした. その他の項目については, 標準值を用いた. 動的QoS制御機能の動作と同時に必要帯域と sizeおよびqual ityの值を測 
定した.また, 場面の変化に対する効果を確認するために, 動的QoS制御機能の動作開始から 60秒後に観察するポイントを変更する実験もあわせて行った.

\section{2 実験結果}

実験した環境の中で最も帯域が狭い $32 \mathrm{kbps}$ の場合の実験結果を示す. 図 2 は, 動的QoS 制御機能によって制御するQOSパラメータ として qualityを選択した場合の実験結果 である.qualityの值が 5 秒間隔で 5 ステッ プずつ変化していき，これに伴い必要帯域 が32kbpsに近づいていく様子が分かる.動 的QoS制御機能を動作させてから 25 秒後に qual i ty 10 まで上がる。送信側ビデオ ツールでは同時に必要帯域が設定帯域の80 \%未満 (この場合には $25.6 \mathrm{kbps}$ 未満) であ るか否かの判断を行っているが, 動作開始 から 30 秒後の判断時に, 必要帯域が $25.6 \mathrm{kbps}$ 以上になっているのでQoSの変更 は行われていない.この後, 図 2 に示すとお り, 帯域をほぼ使い切った状態で安定して いることが分かる。

図 3 は, 動的QoS制御機能によって制御す るQ0Sパラメータとして sizeを選択した場 合である。ここで, size 1を1/6CIF, size 2 を $2 / 6 \mathrm{CIF}$, size 3 を $4 / 6 \mathrm{CIF}$, size 4 を CIF とする.sizeが 5 秒間隔で 1 段階ずつ変 化していき,これに伴い必要帯域が32kbpsに 近づいていく様子が分かる.動的QoS制御機 能を動作させてから 20 秒後の判断時に,必要 帯域が設定帯域の $80 \%$ 以上（この場合には $25.6 \mathrm{kbps}$ 以上）あるため，この後，QoSの変 更は行われていない. 図 3 に示すとおり, sizeに4/6CIFが設定され，带域をほぼ使い 切った状態となっていることが分かる.

図 4 は, 場面の変化に対する動的QoS制御 機能の有効性を確認するための実験結果であ る. $32 \mathrm{kbps}$ での結果を示す。この実験は, 動 的 QoS 制御機能の動作を開始してから 60 秒 後に観察ポイントを変更したものである.制

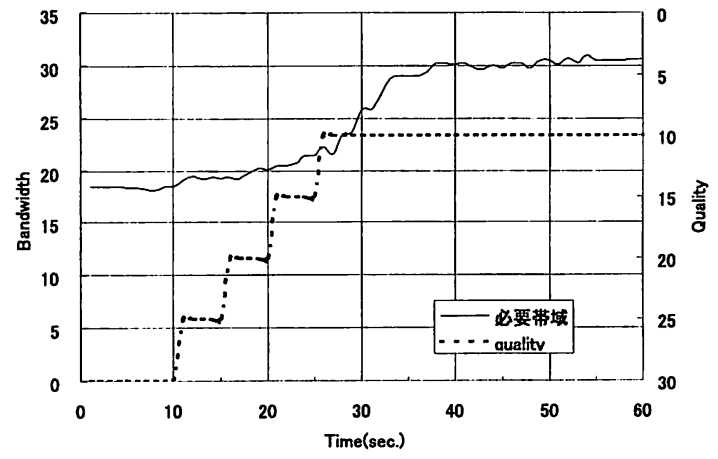

図 2. 実験結果 1

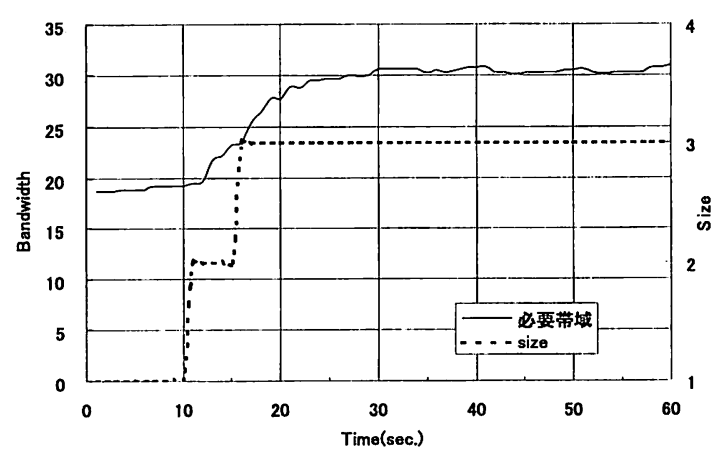

図 3 . 実験結果 2

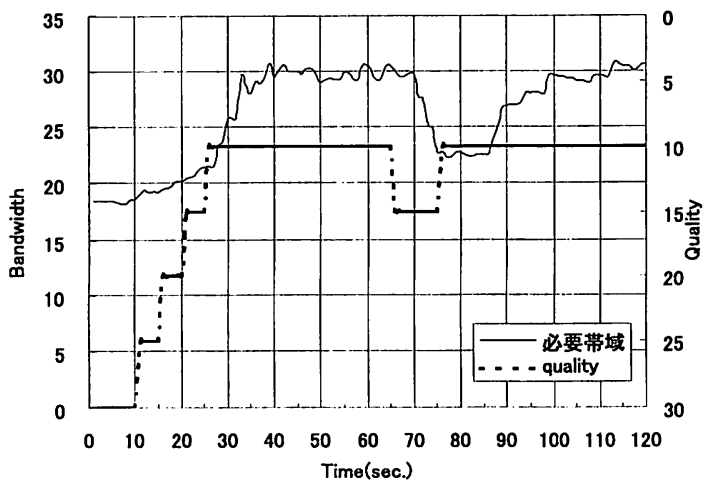

図 4 . 実験結果 3 
御するQoS パラメータにはquality を選択した. 図 4 に示すとおり, 動的QoS 制御機能の動 作開始から 25 秒で, qual i tyに10が設定され, 安定した状態となっている.この後, 動作開 始から 60 秒後に観察ポイントの変更を行った。この結果, 動作開始から65秒後の判断時に, qual i tyを 15 まで下げている.これは, フレームレートの最低確保值が5fpsを下回ったため である. その後, 動作開始から 75 秒後には, qualityが10に戻っている.この後, 必要帯域 が25.6kbps (設定帯域の $80 \%$ ) 以上であるのでQoSの変更は行わない.この実験結果から,開 発した動的Q0S制御機能は, 場面の変更に対しても有効に機能していることが分かる.

図 2 から図 4 において32kbpsでの実験結果を示したが,他の帯域についても同様な結果が 得られ,いずれの帯域においても開発した機能の効果は十分に実証できる.

\section{5 . 考察}

提案した動的QoS制御機能は,狭帯域回線の上で有効に機能することが示された.通信開始 時のQoS設定值が適当な值であっても, 利用者の要求に応じて選択されたQoSパラメータを, ルールにしたがって変更し, 可能な限り多くの情報を転送している.これにより,QoSパラメー 夕の設定作業が不要になり,利用者の作業が軽減される.さらに場面の変化に対しても有効に 機能していることが確認できた. 提案機能を有していないビデオッールを用いた場合, 利用者 がビデオツールを操作し, 場面と帯域に応じた画像が得られるように, Q oS 設定・変更作業 を行う必要があった.観察を進めながら,QoS変更作業を同時に行うことは複雑で困難である ため,最初に設定したQoSの值をそのまま使い,この結果, 接続している回線の帯域に対して， 設定が適切でなく,帯域が大きく不足する,または, 逆に帯域が余るといった状況が発生して いた. 提案機能により，QoSの設定・変更作業を省き，かつ帯域を有効に利用した動画像通信 が実現できる。

また,本システムでは, 注目領域と非注目領域の画像のQOSを別に設定することが可能であ るため, 注目領域はカラーで高品質な画像とし, 非注目領域は白黒で低品質な画像を得ること ができる.この画像に対しても動的QoS制御機能は有効に機能する.この場合, 注目領域の QoSについて動的QoS制御機能が働く. 例えば, 変更するパラメータにsizeを選択すると, 帯 域とフレームレートが許す範囲まで, カラーで高品質な画像 (注目領域)の範囲が広くなり, 利用者に,より観察しやすい環境の提供が可能となる.

今回の実験では, QoSを変更する時間間隔を約5秒に 1 回としたが,この時間間隔は自由に設 定することができる.この時間間隔を短くすることにより,場面の変化などに迅速に対応でき る. また, qualityの変更のステップを, 今回の実験では5ステップずつとしたが, このステッ プ間隔を小さな值にすることで,より細かな設定が可能となる.sizeについても同様に, ステッ プの間隔を細かくしステップ数を増やすことで,よりスムーズな画像の表示が可能となる.

また, 本画像通信システムをWebブラウザーからコントロールできれば, 一般のユーザに とって,より利用しやすい環境が提供できる.Webブラウザーからの利用が可能となると, WWW を利用した他の情報システムとの連携が実現でき,ユーザはより的確な情報をすばやく収集す ることが可能となる. 


\section{6. おわりに}

本論文では, 農業情報のための動画像通信システムに適した動的QoS制御機能について述べ た.この機能をビデオツールに実装し，3つの帯域に対して実験を行った. 実験結果より，い ずれの帯域においても,提案した機能が有効に働き,与えられた帯域の中で可能な限り多くの 情報を利用者に提供することができ,ネットワーク帯域の有効な利用が可能であることを確認 した.この機能は, RSVPやIPv6などの帯域予約ができる環境において, 確保した帯域を有効 に利用する手段としても期待できる. さらに, 通信開始時のQoS設定や場面変更時のQoS設定 作業が不要となるため, 利用者の作業の軽減が図れる.今回は, 注目領域の選択範囲と量子化 係数を動的に変更するQoSパラメータとし, 動的QoS機能を実現した. 今後は, これらの值を 変更するステップ数やQoS変更のタイミングなどについての検討, およびその他のパラメータ についての検討を進めるとともに, 農業情報の多くの分野に利用し, 利用目的に対応した動的 QoSのポリシーの提案とシステムの評価を行っていく予定である.

\section{7. 引用文献}

1）二宮正士・木浦卓治・江渡浩一郎・南石晃明・上田正和（1997）：WWW 圃場画像獲得システム, 植物工 場学会誌9(1): 12-19.

2）井口信和・内尾文隆・亀岡孝治（1998a）：病害虫の遠隔診断システム(第 1 報)システム構成と画像通信 機能の評価, 農業情報研究, 第 7 巻 1 号: 1-12.

3 ）井口信和・内尾文隆・亀岡孝治 (1998b)：病害虫の遠隔診断システム (第2 報)注目領域の選択機能, 農 業情報研究, 第 7 巻 1 号: 13-20.

4) Iguchi, N., Uchio, F., Kameoka, T., (1998): Remote Examination System for Plant Diseases using Video Communication, Proceeding of AFITA:113-117.

5) テレビジョン学会編 (1993) : 画像情報圧縮, 原島博監修, オーム社

6) McCanne, S. and Jacobson, V. (1995): vic: A Flexible Framework for Packet Video, Proceeding of ACM Multimedia' 95.

7) Jacobson, V. and McCanne, S. R. (1996): video conferencing tool. Lawrence Berkeley Laboratory. Software on-line. ftp://ftp. ee.lbl. gov/conferencing/vic.

8) Schulzrinne, H., Casner, S., Frederick, R., Jacobson, V., (1996) : RTP:A Transport Protocol for Real-Time Applications, Internet Engineering Task Force, Audio-Video Transport Working Group, RFC1889.

9) Simpson, W. (1994): The Point-to-Point Protocol (PPP), Internet Engineering Task Force, Network Working Group, RFC1661.

10) Sklower, K., Lloyd, B., Carr, D., Coradetti, T. (1996): The PPP Multilink Protocol (MP) , Internet Engineering Task Force, Network Working Group, RFC1990. 


\section{Dynamic Image Control Function on Video Communication System for Agricultural Informatics}

\section{Nobukazu Iguchi ${ }^{*}$, Fumitaka Uchio ${ }^{* *}$, Takaharu Kameoka ${ }^{* * *}$}

"Industrial Technology Center of Wakayama Prefecture, 60 Ogura, Wakayama, Wakayama 6496261, Japan

"*Faculty of Systems Engineering, Wakayama University,930 Sakaedani, Wakayama, Wakayama 640-8510, Japan

${ }^{* * *}$ Faculty of Bio-resources, Mie University, 1515 Kamihama-cho, Tsu, Mie 514-8507, Japan

\section{Summary}

This paper describes a dynamic image control function on video communication system for agricultural informatics. The video communication system is used for remote diagnosis of diseases and pests and remote observation of remotely located fields. The main feature of the proposed function is that the function can dynamically control size and quality of video images according to a user's demands and purposes. The proposed function does not need to adjust QoS parameters. Furthermore, the proposed function can transmit the video images effectively for an assigned network by controlling the QoS parameters to fit them into the network. We experimented on three different bandwidth networks using the proposed function. From experimental results, we verified that the proposed function worked finely on any bandwidth and transmits the video images to the best on the assigned network bandwidth.

Keywords: Image control function, Dynamic QoS Control, video communication, computer networks, agricultural informatics, remote diagnosis system 